\title{
IMPROVED LLM METHODS USING LINEAR REGRESSION
}

\author{
Zihang Zhao ${ }^{1}$, Wenhui Lang ${ }^{1}$, Anthony Paul Doulgeris ${ }^{2}$, Lu Chen ${ }^{1}$ \\ 1.School of Computer and Information of Hefei University of Technology, Hefei, China \\ 2.Department of Physics and Technology, University of Tromsø-The Arctic University of Norway, Tromsø, Norway
}

\begin{abstract}
This paper is focused on investigations of the improved correction of the effect of variation in incidence angle on ScanSAR data. Conventional correction methods (such as LLM, locally linear mapping) typically assume that each target class has a similarity distribution in the middle of the image. The objectives of this study are to extend the correction algorithm to full swath width without any assumptions. For a target class only distributed on one or both sides of the image, interpolation or extrapolation of the confidence interval is realized using the linear regression technique based on the exponential model. The position of the reference band is then determined and the correction is performed. Experiments were performed on ENVISAT ASAR and RADARSAT-2 ScanSAR data. The results show the effectiveness of the proposed method.
\end{abstract}

Index Terms-ScanSAR, sea ice, incidence angle correction, linear regression

\section{INTRODUCTION}

Sea ice monitoring is very important for climate research, shipping traffic and marine resource development. Synthetic Aperture Radar is an important tool for sea ice monitoring with its unique day and night imaging capability. Among its various modes of operation, ScanSAR mode is widely used as the main means of large-scale observation. However, there is a significant incidence angle effect in Wide Swath Mode, that is, the radar returns will be stronger in the close range and decrease progressively towards the far range. This effect will affect the interpretation of ScanSAR data.

Several methods of efficiently compensating for variations of the incidence angle have been proposed, including cosinebased corrections [1] and other empirically based approaches [2], [3]. The look up table (LUT) technique can be applied to adjust recorded backscatter intensities to a nominal incidence angle [4]. Class-based normalization was first introduced in [5]. A normalization approach called HIST, which is based on a class histogram matching procedure, was proposed by [6] to adjust multi-incidence Uninhabited Aerial Vehicle Synthetic Aperture Radar (UAVSAR) data to a fixed angle of incidence. Additionally, the class-based locally linear mapping (LLM) technique is remarkable, and each class in ScanSAR data can be normalized to a nominal incidence angle in the middle of the image [7]. However, the assumption that sea ice types have similarity distributions in the middle of the image may often be invalid. This work extends the correction algorithm of [7] to the whole incident angle range of the image without any assumptions.

The paper is organized as follows: Section 2 details the procedure of the proposed method. Experimental results are given in Section 3 and conclusion in Section 4.

\section{METHOD}

First of all, a binary mask for each class in the original image is constructed. For the convenience of discussion, the masks in this paper are currently performed manually based on the ice chart and expert knowledge. Similar to the steps described in the LLM algorithm, the analysis unit for radar backscattering is the azimuth band of incidence angle. Each band in the image represents $1^{\circ}$ of the incidence angle's observation, and the backscatter coefficients ( $\sigma^{\circ}$ values) for a particular target class in each band are numerically sorted. The sorted values are then divided into $\mathrm{N}$ subsets and the mean of each subset is calculated. The selection of $N$ depends on the numerical range of the $\sigma^{0}$ values and should be consistent across all azimuth bands.

When $\mathrm{N}$ is large enough, the $\sigma^{\circ}$ values within each subset are considered to be locally linear, so that these values in an actual azimuth band can be mapped into the corresponding subset in the reference band. In the actual azimuthal band, the difference between the $\sigma^{\circ}$ value of a pixel and the $N$ mean values are calculated, and the mean value closest to the pixel value is what we need to map. 
The distance between classes is determined by the selection of the reference band. In general, a reference band is selected approximately half of an image. But if the reference band of all ice classes is placed at the center of the image or a fixed angle, it is difficult to achieve the maximal difference between the $\sigma^{\circ}$ values of different target classes. Therefore, for each target class with a range of incidence angles from $\theta_{\text {near }}$ to $\theta_{\text {far }}$, it is assumed by LLM that more than one azimuth band occurs within the interval $\left[\left(3 \theta_{\text {near }}+\theta_{\text {far }}\right) / 4\right.$, $\left.\left(\theta_{\text {near }}+3 \theta_{\text {far }}\right) / 4\right]$, which has a similar distribution of the target class. However, the above assumption may often be invalid, for example, when a target class is only distributed in the upper and lower $1 / 4$ interval, or only within one of the intervals. Consequently, the proposed method will interpolate or extrapolate the interval $\left[\left(3 \theta_{\text {near }}+\theta_{\text {far }}\right) / 4\right.$, $\left.\left(\theta_{\text {near }}+3 \theta_{\text {far }}\right) / 4\right]$ using the linear regression technique and determine the reference band position corresponding to such distribution.

The exponential model is based on extensive measurements at the University of Kansas [8]. Through experiments, it is found that the average change of the scattering coefficient of the North American terrain in summer has such an exponential relationship. Ulaby also reported a similar relationship, and pointed out that the exponential form is suitable for snow-covered areas and sea ice observations [9]. It seems that exponential model is the best one of the many experimental models. The model is defined as follow [8]:

$$
I=I_{0} \mathrm{e}^{-\theta_{i} / \theta_{0}}
$$

where $I$ is the surface intensity observed, $I_{0}$ is the intensity (brightness) of an ideal reflector at the observation

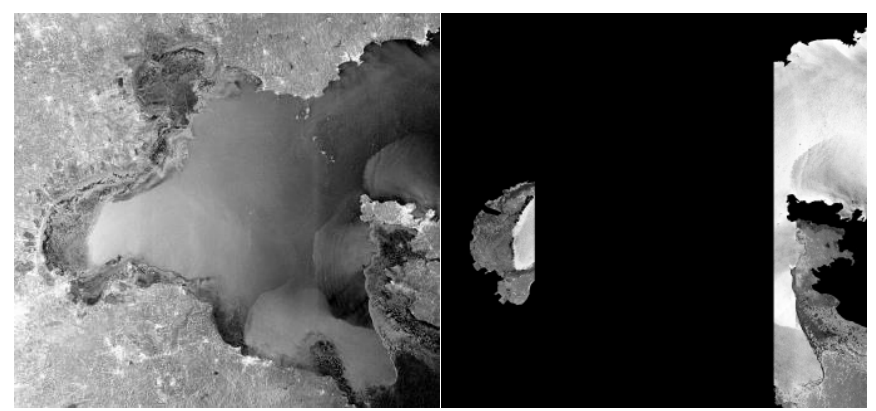

(a) Original image

(b) After correction wavelength, $\theta_{1}$ is the wave incident angle and $\theta_{0}$ is the constant associated with a target class.

A better estimation of $\theta_{0}$ was sought as it will produce the best fitting curve along the range. For this purpose, the coefficients of a linear regression model were calculated with the following regression equation:

$$
y=m x+n
$$

where $y=10 \log _{10} I=\sigma^{0}, x=\theta_{i}, m=\left(-\frac{10}{\theta_{0}}\right) \log _{10} e$, $n=10 \log _{10} I_{0}$. The coefficients $m$ and $n$ can be estimated using least squares.

\section{RESULT AND ANALYSIS}

The experimental data used in this paper are provided by the ASAR instrument on ENVISAT satellites and the RADARSAT-2. Two Bohai Bay images were collected by ENVISAT ASAR ScanSAR with a swath width of $400 \mathrm{~km}$ and a spatial resolution of $150 \mathrm{~m}$. One was acquired on January 31, 2010, with a descending right-looking orbit for which the range increases from east to west; another image was acquired over the same area on January 14, 2010, during which the range distance increased towards the east. To facilitate the interpolation, the pixels within the interval $\left[\left(3 \theta_{\text {near }}+\theta_{\text {far }}\right) / 4,\left(\theta_{\text {near }}+3 \theta_{\text {far }}\right) / 4\right]$ are filled with white color. The RADARSAT-2 data was acquired over the Gulf of Saint Lawrence on February 27, 2009(centered at 48 $47^{\prime}$ N, 60 $58^{\prime}$ $\mathrm{W}$ ), and it has a wide incidence angle ranging from $23^{\circ}$ to $46^{\circ}$. In the image, open water is distributed only in the interval $\left(\left(\theta_{\text {near }}+3 \theta_{\text {far }}\right) / 4, \theta_{\text {far }}\right]$. The result of experiments of average backscattering $\sigma^{\circ}$ using linear regression technique are shown in Fig.1-3 and table1:

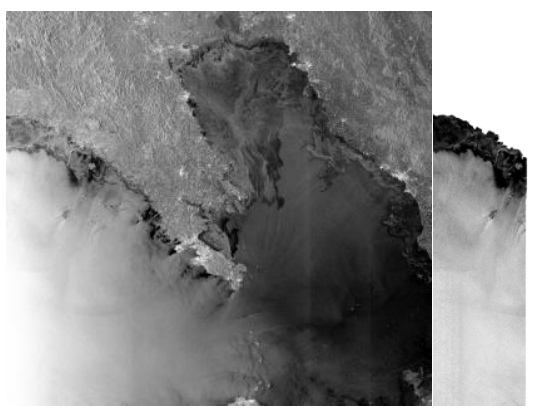

(c) Original image

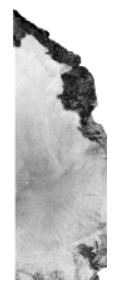

(d) After correction 


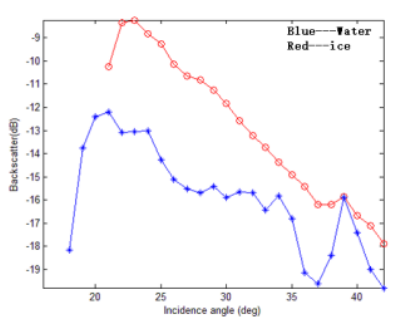

(c) Original backscatter

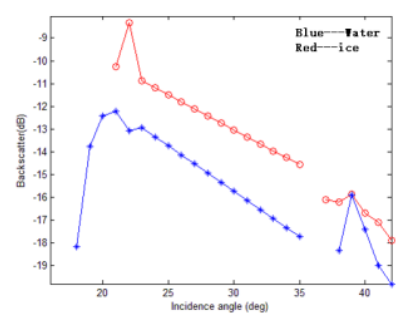

(d) Backscatter after correction

Fig1. Bohai Bay data (201400114)

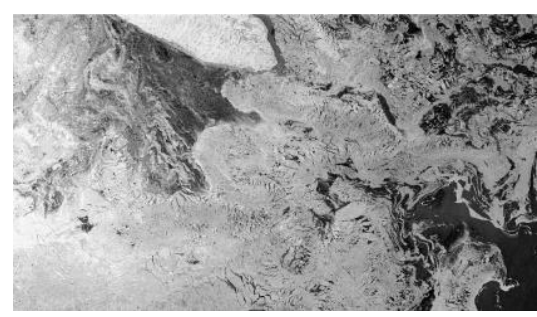

(a) Original image

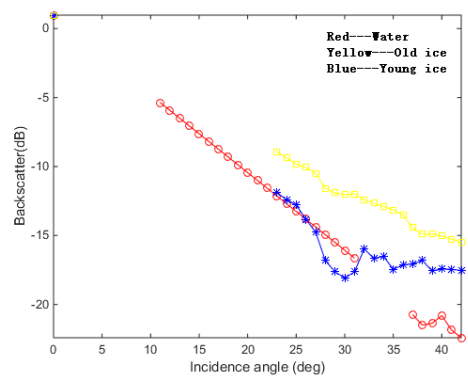

(c) Original backscatter

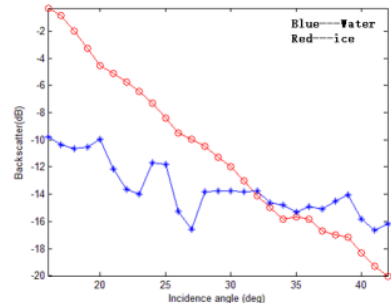

(c) Original backscatter

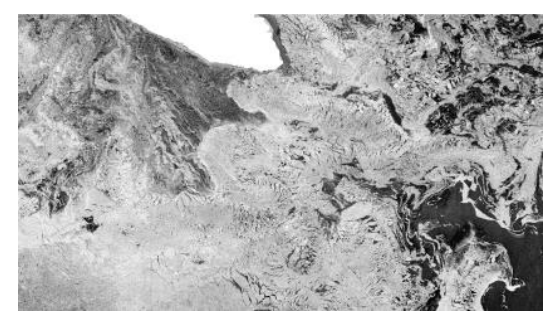

(b) After correction

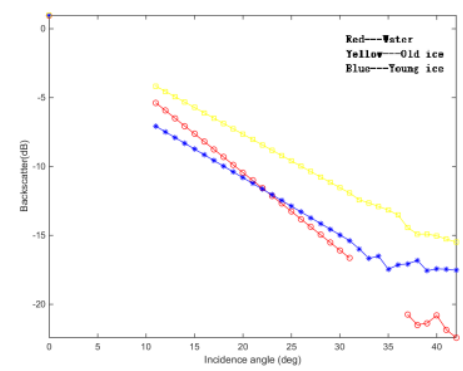

(d) Backscatter after correction

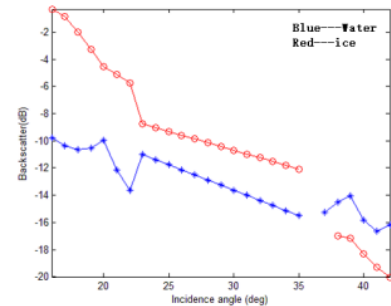

(d) Backscatter after correction

Fig3. The gulf of Saint Lawrence before correction and after correction

Table1. Corrected results using linear regression

\begin{tabular}{|c|c|c|c|c|c|c|}
\hline \multicolumn{2}{|c|}{ Date/class } & $\mathrm{m}$ & $\mathrm{n}$ & $\theta_{0}$ & $\operatorname{Ref}_{\text {angle }}$ & $\operatorname{Ref}_{\text {ori }}$ \\
\hline \multirow{2}{*}{$\begin{array}{c}\text { Bohai } \\
\text { Bay(20100114) }\end{array}$} & Water & -0.43613 & 0.63348 & 2.2929 & $23^{\circ}$ & $23^{\circ}$ \\
\hline & Ice & -0.20663 & -9.6842 & 4.8397 & $35^{\circ}$ & $36^{\circ}$ \\
\hline \multirow{2}{*}{$\begin{array}{c}\text { Bohai } \\
\text { Bay(20100131) }\end{array}$} & Water & -0.73147 & 10.8224 & 1.3671 & $23^{\circ}$ & $23^{\circ}$ \\
\hline & Ice & -0.21228 & -7.2052 & 4.7107 & $35^{\circ}$ & $27^{\circ}$ \\
\hline \multirow{3}{*}{$\begin{array}{c}\text { The gulf of Saint } \\
\text { Lawrence }\end{array}$} & Water & -0.5631 & -2.6750 & 1.7760 & $25^{\circ}$ & $11^{\circ}$ \\
\hline & Young ICE & -0.4152 & -2.5051 & -2.5051 & $19^{\circ}$ & $23^{\circ}$ \\
\hline & Old Ice & -0.3878 & 0.1032 & 2.5786 & $19^{\circ}$ & $23^{\circ}$ \\
\hline
\end{tabular}

Quantitative analysis is necessary in order to evaluate the efficiency of this method, we introduce the RMSE (root mean square error), which is defined as follows:

$$
R M S E=\sqrt{\left[\left(\sigma_{\text {norm }}^{\circ}-\sigma_{\text {act }}^{\circ}\right)^{2}\right]}
$$

Where $\sigma_{a c t}^{\circ}$ and $\sigma_{\text {norm }}^{\circ}$ are radar backscatter values before correction and after correction and expressed in $\mathrm{dB}$; “-” represents mean value. The RMSE values for each experiment are shown in Fig.4-6: 

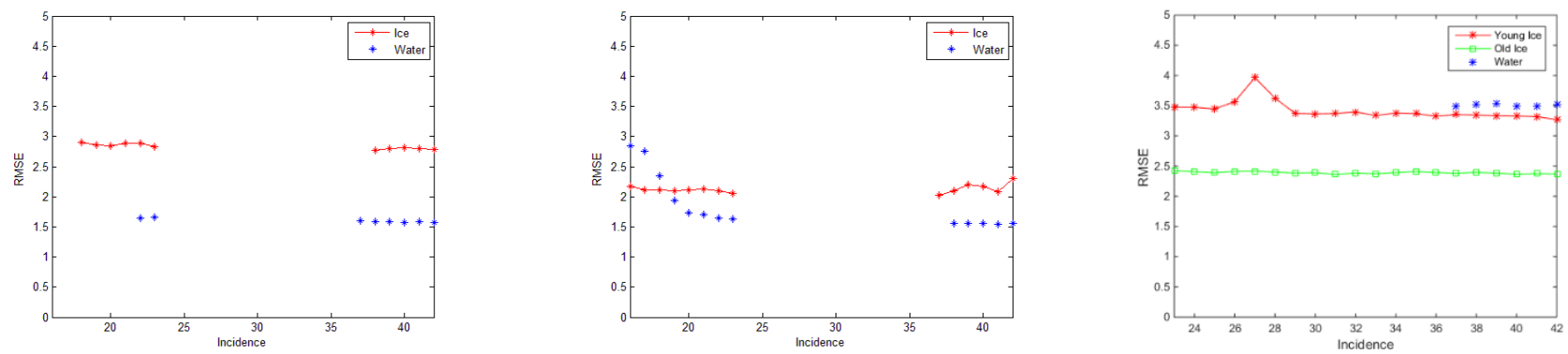

Fig.4 The Bohai Bay(20100114) RMSE Fig.5 The Bohai Bay(20100131) RMSE Fig.6 The gulf of Saint Lawrence RMSE

Through the RMSE analysis of three images, it is not difficult to see that the correction effect of SAR sea ice image is valid by combining linear regression and LLM method.

\section{CONCLUSION}

In this paper, we have improved the LLM method through the linear regression technique. From the experimental results, we can see that for the image that is distributed outside $\left[\left(3 \theta_{\text {near }}+\theta_{\text {far }}\right) / 4,\left(\theta_{\text {near }}+3 \theta_{\text {far }}\right) / 4\right]$ in the image, the improvement is obvious and effective, but for the junction parts between $\left[\left(3 \theta_{\text {near }}+\theta_{\text {far }}\right) / 4,\left(\theta_{\text {near }}+3 \theta_{\text {far }}\right) / 4\right]$ internal and external,the results is still not smooth enough, This will be studied in future work.

\section{ACKNOWLEDGEMENTS}

This work was supported in part by the National Natural Science Foundation of China under Grants No.61271381, No.61371154 and No.61102154. A.P. Doulgeris has been funded by the Norwegian Research Council (NFR) through the Centre for Integrated Remote Sensing and Forecasting for Arctic Operations (CIRFA) (NFR project number 237906).

\section{REFERENCES}

[1] F. T. Ulaby, R. K. Moore, and A. K. Fung, Microwave Remote Sensing: Active and Passive, Volume II-Radar Remote Sensing and Surface Scattering and Emission Theory. Norwood, MA, USA: Artech House, 1982.

[2] J. Van doninck, W.Wagner, T. Melzer, B. De Baets, and N. E. C. Verhoest, "Seasonality in the angular dependence of ASAR wide swath backscatter," IEEE Geosci. Remote Sens. Lett., vol. 11, no. 8, pp. 1423-1427, Aug. 2014.

[3] Zakhvatkina N, Korosov A, Muckenhuber S, et al, "Operational algorithm for ice/water classification on dual- polarized RADARSAT-2 images," Cryosphere Discussions, 1-22, 2016.

[4] C. H. Menges, G. J. Hill, W. Ahman, and J. J. van Zyl, "Incidence angle correction of AIRSAR data to facilitate land-cover classification," Photogramm. Eng. Remote Sens., vol. 67, no. 4, pp. 479-490, Apr. 2001.

[5] J. P. Ardila, V. Tolpekin, and W. Bijker, "Angular backscatter variation in L-band ALOS ScanSAR images of tropical forest areas," IEEE Geosci. Remote Sens. Lett., vol. 7, no. 4, pp. 821-825, Oct. 2010.

[6] I. E. Mladenova, T. J. Jackson, R. Bindlish, and S. Hensley, "Incidence angle normalization of radar backscatter data," IEEE Trans. Geosci. Remote Sens., vol. 51, no. 3, pp. 1791-1804, Mar. 2013.

[7] Lang W, Zhang P, Wu J, et al, "Incidence Angle Correction of SAR Sea Ice Data Based on Locally Linear Mapping," IEEE Trans. Geosci. Remote Sens., vol. 54, no. 6, pp. 3188-3199, Jun. 2016.

[8] Moore, R. K., K. A. Soofi, and S. M. Purduski, "A radar clutter model: Average scattering coefficients of land, snow, and ice," IEEE. Trans. Aerospace and Electronics System, vol. 16, no. 6, pp.783-789, Nov. 1980.

[9] Ulaby, F. T., "Vegetation Clutter Model," IEEE Trans. Antennas and Propagation, vol. 28, no. 4, pp. 538-545, Jul. 1980 . 